\title{
Remineralization potential and mechanical evaluation of a bioactive glass containing composite (An ex vivo study)
}

\author{
Nouran Hussein ${ }^{1 *}$ D , Dina A. El Refai ${ }^{2}$, Ghada Atef Alian ${ }^{2}$ \\ ${ }^{1}$ Dental Materials Department, Faculty of Dentistry, British University in Egypt (BUE), Cairo, Egypt; ${ }^{2}$ Department of Biomaterials, \\ Faculty of Dentistry, Ain-Shams University, Cairo, Egypt
}

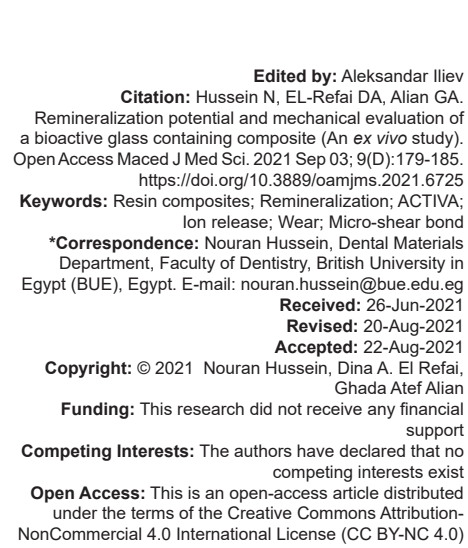

\begin{abstract}
AIM: The aim of the study was to compare the remineralization ability, ion release, micro-shear bond strength, and wear resistance of a claimed bioactive restorative material (ACTIVA BioACTIVE Restorative) with the conventional resin composite (Filtek Z350 XT).

MATERIALS AND METHODS: The remineralization ability was evaluated after 28 days using energy-dispersive X-ray (EDX) analysis. Ion release was investigated at 3 time intervals: 1, 14, and 28 days. Calcium and phosphate ion releases were determined by using ion chromatography system. Micro-shear bond strength was assessed using a universal testing machine. A dual-axis chewing simulator was used to assess the wear resistance of the study materials.

RESULTS: ACTIVA ${ }^{\mathrm{TM}}$ was found to induce the remineralization of demineralized dentin. The obtained data revealed that ACTIVA ${ }^{T M}$ released $\mathrm{Ca}^{2+}$ and $\mathrm{PO}_{4}^{-3}$ ions, while Filtek $\mathrm{Z350}$ XT did not. Concerning micro-shear bond strength $\mathrm{ACTIVA}^{\mathrm{TM}}$ without adhesive application showed unacceptable failure. Regarding wear resistance, there was no
\end{abstract} statistically significant difference between them.

CONCLUSION: ACTIVA ${ }^{\mathrm{TM}}$ BiOACTIVE Restorative material seems a promising bioactive restorative material. Clinical studies are recommended to compare the clinical performance of ACTIVA ${ }^{\mathrm{TM}}$ to other restorative materials.

\section{Introduction}

During the entire life of an individual, the processes of demineralization and remineralization coexist in teeth. However, demineralization outweighs remineralization in pathological conditions. The remineralization of demineralized dentin is a process in which minerals are restored through inorganic minerallike materials formation. Calcium-based compounds were efficiently incorporated into dental restorations to enhance the healing of dental tissues [1], [2], [3].

Dental resin composites are the most popular dental materials used for replacing the damaged tooth structure, since it can esthetically mimic natural teeth. Resin composites are polymer-based materials containing finely ground reinforcing glass or silica [4], [5], [6], [7], [8], [9]. However, the integrity and durability of the resin-dentin interface during aging is the most critical problem that could impair their esthetic appearance and clinical performance [10]. Therefore, a crucial demand is required to achieve effective caries prevention through novel restorative materials and techniques. The new advancement of the commercially resin-based composites depends mainly on modifications of the organic matrix and or inorganic fillers [11].
The development of restorative "smart" materials able to elicit the remineralization of demineralized dentin is an important necessity for operative and preventive dentistry [12]. Larry Hench between 1969 and 1971 was the first to discover the first bioactive material [13], [14]. Since then, there was an alteration in the idea of the materials used for tissue replacement to be bioactive instead of being bioinert. Henceforth, there was a bioactive material growth including modified bioactive glass and calcium phosphate [15], [16]. The biomimetic remineralization strategies implementation, also the use of therapeutic biomaterials has been recommended as possible methods for the caries-affected dentin remineralization, with minimal removal of caries extending the mineraldepleted bonded-dentin interface longevity [10], [17], [18].

Newly, innovative restorative materials are fabricated with impregnation of a bioactive constituent to induce bioactivity such as bioactive glasses, hydroxyapatite, and other calcium phosphate-based fillers. These fillers have a great potential to elaborate calcium and phosphorus ions which is the main source to create bioactivity and remineralization [19].

A bioactive resin-based composite (ACTIVA BioACTIVE Restorative, Pulpdent Corporation, Watertown, USA) was recently introduced, and the 
manufacturer claims that this restorative material is the first bioactive dental material that contains bioactive fillers and an ionic resin matrix simulating the natural teeth's chemical and physical properties [20]. Taking into consideration the innovation of materials in the market, a clinician usually has doubtfulness regarding choosing the best materials to attain ideal results. Therefore, the aim of the current study is to compare the essential properties of a bioactive composite $\left(\right.$ ACTIVA $^{\mathrm{TM}}$ ) such as remineralization, ion release, micro-shear bond strength, and wear resistance to those of Filtek Z350 XT which represents the most commonly used conventional resin composite.

\section{Materials and Methods}

\section{Dentin remineralization testing}

\section{Specimens' preparation}

Split Teflon molds with circular-shaped central holes of dimensions ( $8 \pm 0.1 \mathrm{~mm}$ in diameter and $1.6 \pm 0.1 \mathrm{~mm}$ in thickness) were used to prepare the specimens, as shown in Figure 1 [21]. First, a celluloid strip was placed on a microscopic glass slide. Then, the mold was placed over them. ACTIVA ${ }^{\mathrm{TM}}$ was dispensed into the central hole of the mold, while Filtek Z350 XT was condensed in a single increment. Another celluloid strip was placed on top of the mold and pressed by another glass slide. A weight of $300 \mathrm{~g}$ was placed over the glass slide for $1 \mathrm{~min}$ to obtain a flat surface free of voids. Then, the weight was removed and the specimen was light cured through the glass slide for 20 $s$ according to manufacturer instructions [22].

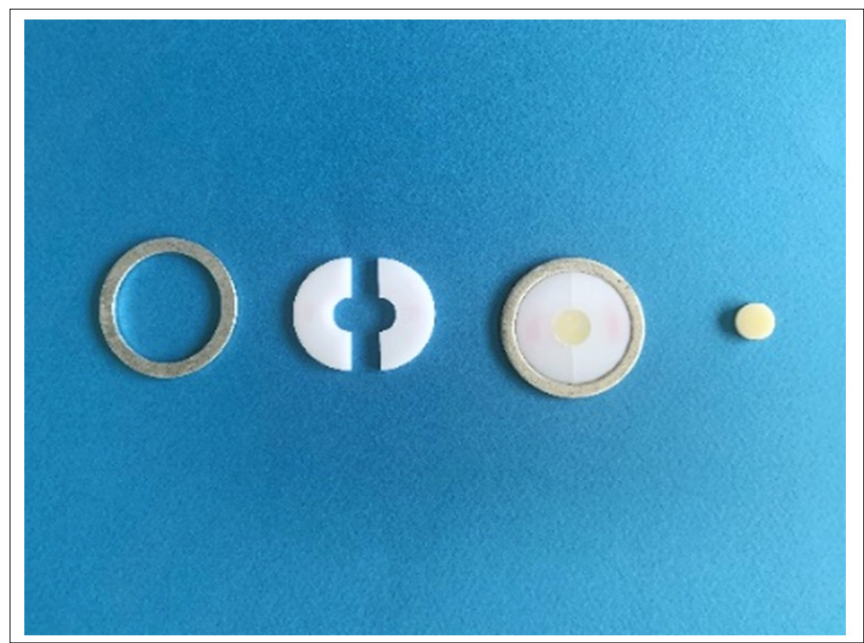

Figure 1: Split Teflon mold

The dentin remineralization ability has been assessed as the capability to induce the formation of an apatite layer on previously demineralized human dentin. Ten sound human premolars extracted for orthodontic or periodontal reasons were collected. Dentin slices
(0.8 $\pm 0.1 \mathrm{~mm}$ thick) were prepared using a linear precision saw (IsoMet 4000, Buehler, Illinois, USA). A single dentin slice was obtained from each tooth $(n=5 /$ group). Dentin slices were then demineralized in $15 \mathrm{~mL}$ of ethylenediaminetetraacetic acid (EDTA) $17 \%$ for $2 \mathrm{~h}$ at room temperature.

A novel setup Gandolfi technique [12] was used for dentin remineralization testing; each material disc, ACTIVA $^{\mathrm{TM}}$ (Group I) and Filtek Z350 XT (Group III), was maintained in close contact with a demineralized dentin slice using a tailored PVC support and soaked in $15 \mathrm{~mL}$ of phosphate-buffered saline (PBS) at $37^{\circ} \mathrm{C}$ for 28 days. After this time, the dentin slice was removed from the support, rinsed with deionized water, and then analyzed in wet conditions by scanning electron microscopy (SEM) and energy-dispersive X-ray (EDX).

Samples were examined with high-resolution environmental scanning electron microscope (Quattro S, Thermo Fisher Scientific, Waltham, Massachusetts, USA), using an accelerating voltage of 10-15 kV. EDX compositional depth profile analysis was implemented through the cross-sectional sample of a longitudinally fractured (perpendicular to the surface) dentin disc. The samples were placed directly onto the SEM stub and examined without preparation. Both dentin disc's surfaces (surface in contact with the composite and opposite free surface) were analyzed [12], [23].

\section{Ion release testing}

\section{Sample size calculation}

Sample size was estimated using $G^{*}$ Power version 3.1.9 based on the p-release data extracted from Awosanya et al., 2014 [24]. The release of the tested groups resulted in large effect size $(f=5.2)$. For sample size analysis at $\alpha=0.05$, the study will have power of $99.5 \%$, which yields a sample size of 3 samples per group. The samples were increased to 5 samples in each group for statistical analysis test reliability.

\section{Specimens' preparation}

The material discs were prepared as mentioned previously using a split Teflon mold (Figure 1). Five-discshaped specimens of each material, Group I (ACTIVA ${ }^{\text {TM }}$ ) and Group III (Filtek Z350 XT) ( $n=5)$, were used for the testing of calcium $\left(\mathrm{Ca}^{2+}\right)$ and phosphate $\left(\mathrm{PO}_{4}{ }^{3-}\right)$ ion release. Each disc was immersed in $15 \mathrm{~mL}$ of deionized water in a sealed $50-\mathrm{mL}$ sterile polypropylene tube and stored in the incubator at $37^{\circ} \mathrm{C}$ [22]. Ion release was measured after 1 day, 14 days, and 28 days. At the time of testing, the specimen was removed from the tube, rinsed with deionized water, and re-immersed in newly fresh $15 \mathrm{~mL}$ of deionized water until the next testing time [23]. The released ions were measured using ion chromatography system and represented in part per million (ppm) concentration units. 


\section{Micro-shear bond strength testing}

\section{Sample size calculation}

Sample size was estimated using $G^{*}$ Power version 3.1.9 based on the data extracted from Arab et al., 2019 [25]. The bond strength of tested groups resulted in large effect size $(f=7.76)$. For sample size analysis at $\alpha=0.05$, the study will have power of $100 \%$, which yields a sample size of 2 samples per group. The samples for shear bond strength were increased to 12 samples in each group for bond strength test reliability.

\section{Specimens' preparation}

Eighteen sound human premolars were extracted for orthodontic or periodontal reasons ( $n=$ 6 teeth/group). Teeth were sectioned at the occlusal third of the crown and approximately $2 \mathrm{~mm}$ below the cementoenamel junction with a diamond disc using copious water irrigation. The resulting dentin specimens were embedded with the coronal surface exposed in polyvinyl chloride tubes using acrylic resin, polished using wet 600 -grit silicon carbide paper for $60 \mathrm{~s}$ to create standardized smear layer, randomly divided into three groups: ACTIVA ${ }^{\text {TM }}$ BioACTIVE composite without adhesive (Group I), ACTIVA ${ }^{\mathrm{TM}}$ with adhesive (Group II), and composite Filtek Z350 XT (Group III) [26].

After the adhesive application, two clear cylindrical Tygon tubing $(0.8 \mathrm{~mm}$ internal diameter $\times$ $1.0 \mathrm{~mm}$ height) were placed on the flat dentin surface of each tooth and subjected to adhesive light curing for $20 \mathrm{~s}$. After curing, each tube was carefully filled with composite, and light irradiated for $20 \mathrm{~s}$ according to manufacturer's instructions. All specimens were then stored in distilled water at $37^{\circ} \mathrm{C}$ in the incubator for $24 \mathrm{~h}$ [27].

Specimens were then mounted to a universal testing machine (Instron 3300, MA, USA) with a load cell of $50 \mathrm{~N}$. A $0.5-\mathrm{mm}$ stainless steel orthodontic wire was looped around the resin composite cylinder and a shear force was applied at a crosshead speed of $1.0 \mathrm{~mm} / \mathrm{min}$ until fracture occurred [28]. Then, the micro-shear bond strength ( $\mu \mathrm{SBS}$ ) was computed and expressed in MPa.

\section{Wear resistance testing}

\section{Sample size calculation}

Sample size was estimated using $G^{*}$ Power version 3.1.9 based on the data extracted from Garoushi et al., 2018 [20]. The wear of tested groups resulted in large effect size $(f=10.52)$. For sample size analysis at $\alpha=0.05$, the study will have power of $100 \%$, which yields a sample size of 2 samples per group. The samples for wear were increased to 5 samples in each group for statistical analysis test reliability.

\section{Specimens' preparation}

Five specimens of each material, Group I (ACTIVA $^{\text {TM }}$ ) and Group III (Filtek Z350 XT) (n=5/group), were prepared in acrylic resin block for localized wear testing. Longitudinal cavities $(20 \mathrm{~mm}$ length $\times 10 \mathrm{~mm}$ width $\times 2 \mathrm{~mm}$ depth) were prepared and then materials were placed as one increment into the prepared cavities and covered with Mylar strip and glass slide before light curing for $30 \mathrm{~s}$ in five separate overlapping portions.

The surfaces were then polished flat using a sequence of ascending grits of silicon carbide papers (\#1000 to \#2000 grit). After storage for 1 day at $37^{\circ} \mathrm{C}$, a two-body abrasive wear test was performed using the chewing simulator CS-4.2 (SD Mechatronik, Feldkirchen-Westerham, Germany). The specimens were embedded in acrylic resin in the lower sample holder for use as antagonistic wear materials (Figure 2).

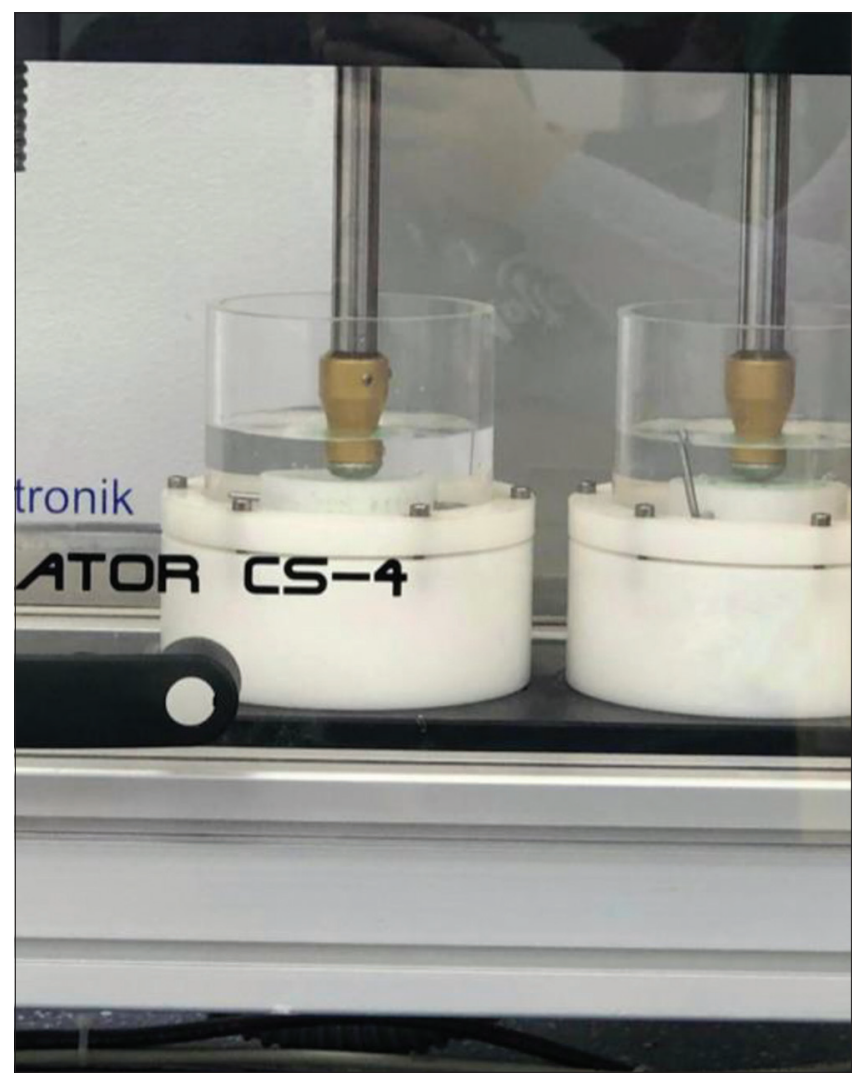

Figure 2: Specimens subjected to wear resistance testing in the chewing simulator CS-4.2 (SD Mechatronik).

The chewing simulator was programmed so that a weight of $2 \mathrm{Kg}$ corresponding to $20 \mathrm{~N}$ of chewing force was applied in each chamber. The frequency of the antagonist movement was set to $1.5 \mathrm{~Hz}$, and 15,000 loading cycles were used [20]. To measure the wear volumes of composite, specimens were scanned with a three-dimensional dental scanner (3Shape, Copenhagen, Denmark) before and after wear testing. Stereolithography (STL) files obtained before and after wear testing were superimposed, and the STL files of wear losses were converted into solid files. Wear volumes were then calculated using a Geomagic software (Geomagic Control X, Geomagic, Cary, NC, USA) [29]. 


\section{Results}

\section{Dentin remineralization}

The EDX compositional depth profile analysis through the fractured demineralized dentin slices showed that the treatment used (EDTA 17\%, $2 \mathrm{~h}$ ) completely removed the mineral phase of dentin to approximately $50 \mu \mathrm{m}$. The EDX results are presented in Figure 3. By examining EDX compositional depth profile of the demineralized dentin after contact with ACTIVA $^{\text {TM }}$ BioACTIVE Restorative for 28 days in PBS, it was observed that $\mathrm{Ca}$ and $\mathrm{P}$ peaks were detected to $\mathrm{a}$ depth of 30-50 $\mu \mathrm{m}$. On the other hand, after examining the other side of dentin surface which was not in contact with ACTIVA ${ }^{\mathrm{TM}}$ BioACTIVE Restorative (ACTIVA $^{\mathrm{TM}}$ untreated side), no $\mathrm{Ca}$ or $\mathrm{P}$ peaks were detected in dentin surface till depth of approximately 30-50 $\mu \mathrm{m}$.

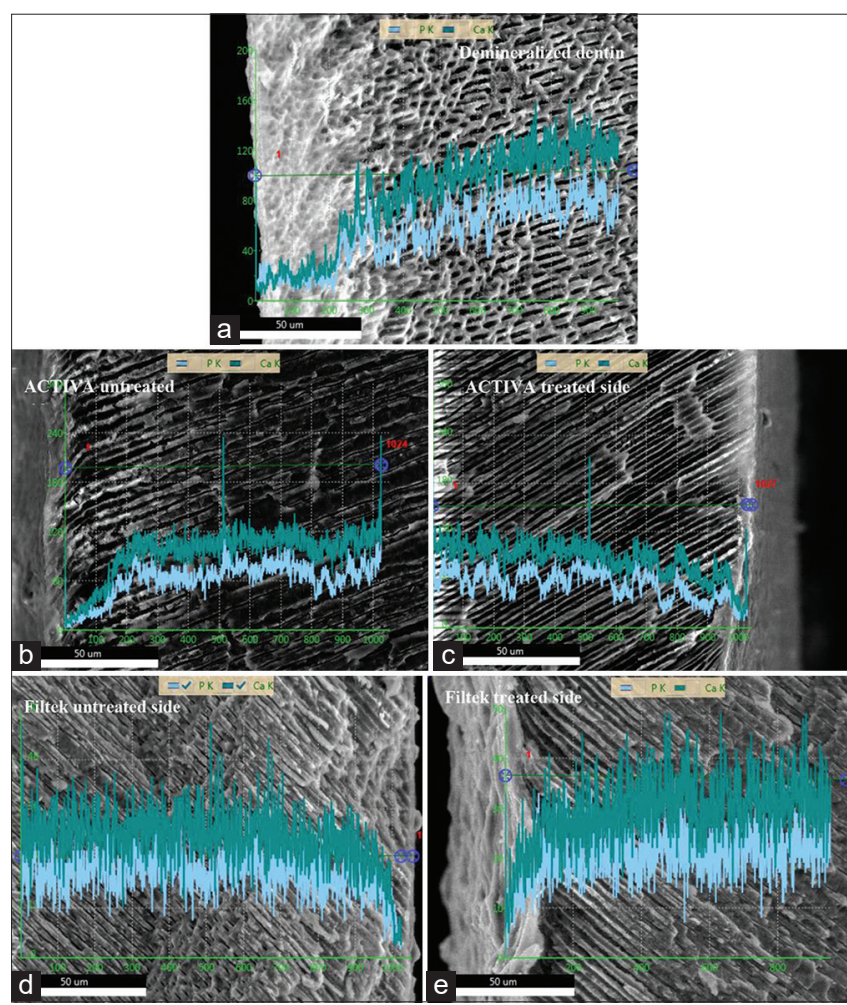

Figure 3: Scanning electron microscopy-energy-dispersive $X$-ray $(E D X)$ of treated and untreated dentin after 28 days of immersion in PBS. EDX compositional depth profile analysis through the crosssectional sample of longitudinally fractured dentin discs: calcium (teal scan lines) and phosphorous (blue scan lines) contents through the dentin thickness were shown. Figure (a) Demineralized dentin. Figure (b) No Ca and P peaks were revealed on the ACTIVA untreated surface. Figure (c) After contact of the demineralized dentin with ACTIVA $^{\mathrm{TM}}$ for 28 days in PBS, dentin remineralization occurred: $C a$ and $P$ peaks were detected on the dentin surface till a depth of 30-50 $\mu \mathrm{m}$. Figure $(d-e)$ No Ca and $P$ peaks were detected on dentin surface till a depth of approx. $50 \mu \mathrm{m}$ after contact with Filtek Z350 XT meaning that no dentin remineralization occurred on the surface in contact and untreated surface as well

EDX compositional depth profile of the demineralized dentin after contact with Filtek Z350 XT for 28 days in PBS revealed no dentin remineralization since no $\mathrm{Ca}$ or $\mathrm{P}$ peaks were detected on the dentin surface in contact with the composite to a depth of approximately 30-50 $\mu \mathrm{m}$. At the meanwhile, after analyzing the depth profiling EDX of the demineralized dentin surface not in contact with Filtek Z350 XT (Filtek untreated side), it revealed no remineralization as $\mathrm{Ca}$ and $\mathrm{P}$ peaks were not detected to a depth of approximately $30-50 \mu \mathrm{m}$.

\section{Ion release}

Mean and standard deviation (SD) values of released calcium and phosphate in ppm are shown in Table 1 and Figure 4. Calcium and phosphate ions were not detected in Filtek Z350 XT group at all time intervals, while calcium and phosphate ions were detected in ACTIVA $^{\mathrm{TM}}$ group at all time intervals. Moreover, there was no significant difference in the values of calcium and phosphate ions among the different time intervals of ACTIVA ${ }^{\mathrm{TM}}$ group.

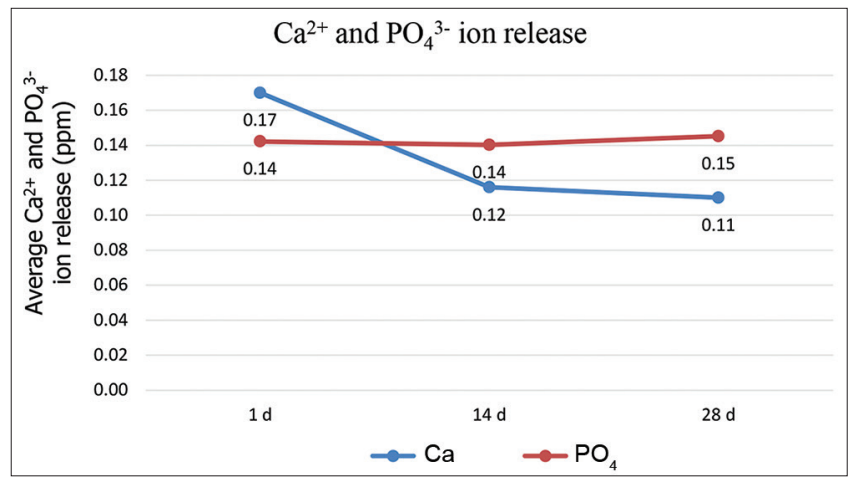

Figure 4: Line chart showing $\mathrm{Ca}$ and $\mathrm{PO} 4$ ion release mean values of ACTIVA group after 1,14 , and 28 days

Table 1: Mean and SD values of $\mathrm{Ca}^{2+}$ and $\mathrm{PO}_{4}{ }^{3-}$ ions in ACTIVA ${ }^{\text {TM }}$ group

\begin{tabular}{|c|c|c|c|c|c|c|c|}
\hline \multirow[t]{2}{*}{ Type of ion } & \multicolumn{2}{|l|}{1 day } & \multicolumn{2}{|c|}{14 days } & \multicolumn{2}{|c|}{28 days } & \multirow[t]{2}{*}{$p$-value } \\
\hline & Mean & $\pm \mathrm{SD}$ & Mean & $\pm S D$ & Mean & $\pm \mathrm{SD}$ & \\
\hline $\mathrm{Ca}^{2+}$ & 0.17 & 0.06 & 0.12 & 0.02 & 0.11 & 0.04 & $>0.05$ \\
\hline $\mathrm{PO}_{4}^{3-}$ & 0.14 & 0.00 & 0.14 & 0.00 & 0.15 & 0.01 & $>0.05$ \\
\hline
\end{tabular}

\section{Micro-shear bond strength}

Means and SDs of the micro-shear bond strength values are presented in Table 2 and Figure 5. One-way ANOVA of the mean values of the micro-shear bond strength $(\mathrm{MPa})$ showed a significant difference at $p<0.001$, followed by Tukey's HSD for pairwise comparison.

Table 2: Means and SD of micro-shear bond strength ( $\mu$ SBS) values in MPa of all the study groups

\begin{tabular}{llll}
\hline Group & \multicolumn{2}{l}{$\mu$ SBS $(\mathrm{MPa})$} & $\mathrm{p}$-value \\
\cline { 2 - 3 } & Mean & $\pm \mathrm{SD}$ & \\
\hline Group I (ACTIVA & \\
Group II (ACTIVA ${ }^{\mathrm{TM}}$ without adhesive) & $7.07^{\mathrm{a}}$ & 1.53 & $<0.001^{*}$ \\
Group III (Filtek Z350 XT) & $7.50^{\mathrm{a}}$ & 2.25 & \\
\hline "Significant. Different superscript letters indicate a statistically significant difference within the same vertical \\
column. SD: Standard deviation.
\end{tabular}

The results of Group III (Filtek Z350 XT) showed a mean micro-shear bond strength (MPa) of 
$7.07 \pm 1.53 \mathrm{MPa}$, compared to Group II (ACTIVA ${ }^{\mathrm{TM}}$ with adhesive) $(7.5 \pm 2.25 \mathrm{MPa}$ ) with no statistically significant difference between them. On the other hand, for Group I (ACTIVA ${ }^{\mathrm{TM}}$ without adhesive), the mean micro-shear bond strength $(\mathrm{MPa})$ was $3.19 \pm 1.46 \mathrm{MPa}$ resulting in statistically significant difference in comparison to both Groups II and III.

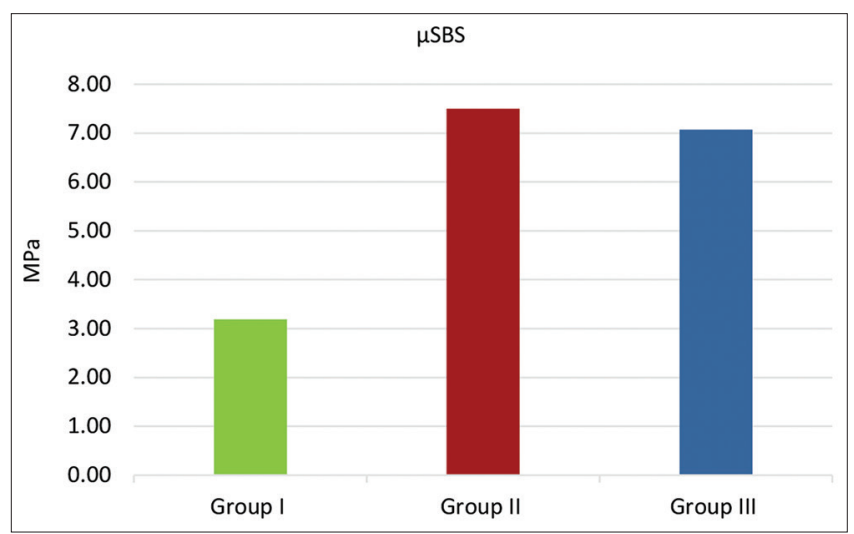

Figure 5: Bar chart showing the micro-shear bond strength ( $\mu S B S)$ mean values for all tested study groups. $\mu$ SBS for different tested groups. Where: Group I is ACTIVA without adhesive, Group II is ACTIVA with adhesive, and Group III is Filtek Z350 XT

\section{Wear resistance}

Means and SD of the volumetric difference in $\mathrm{mm}^{3}$ (wear) values for both types of dental restoratives after being subjected to the chewing simulator used in the study are presented in Table 3 and Figure 6. Wear results showed normal distribution, so independent t-test was used to compare between the tested groups.

Table 3: Means and SD volumetric wear difference values in $\mathrm{mm}^{3}$ of Groups I and III

\begin{tabular}{llll}
\hline Group & \multicolumn{2}{l}{ Volume (Diff) } & p-value \\
\cline { 2 - 3 } & Mean & \pm SD & \\
\hline Group I (ACTIVA ${ }^{\text {TM }}$ ) & 0.089 & 0.015 & $>0.05$ \\
Group III (Filtek Z350 XT) & 0.093 & 0.030 & \\
\hline$p>0.05$ (non-significant). SD: Standard deviation & &
\end{tabular}

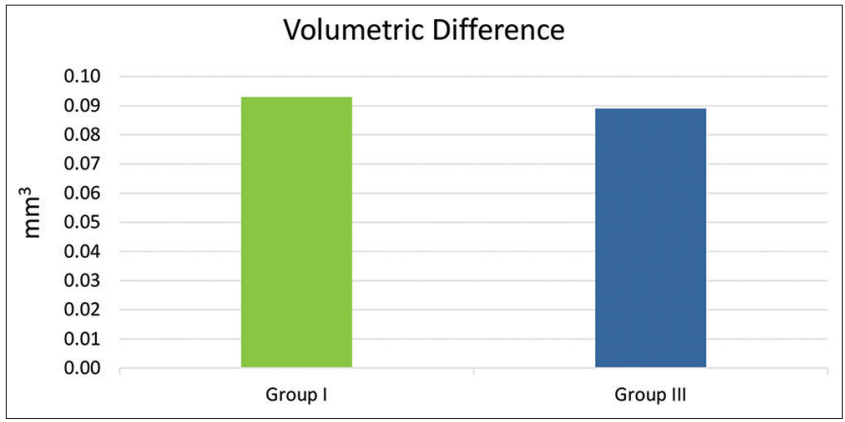

Figure 6: Bar chart showing the mean volumetric wear values for all tested study groups. Wear for different tested groups. Where: Group I is ACTIVA and Group III is Filtek Z350 XT

Group III (Filtek Z350 XT) showed mean wear of $0.089 \pm 0.015$, compared to Group I (ACTIVA ${ }^{\text {TM }}$ ) with mean wear of $0.093 \pm 0.030$. On observing the obtained results, there was no statistically significant difference between both groups.

\section{Discussion}

There is a lack of commercially available composites with proclaimed and verified remineralizing activity. Thus, the conducted study aimed to assess the bioactive ionic resin-based composite (ACTIVA ${ }^{\mathrm{TM}}$ BioACTIVE Restorative) regarding its bioactivity through the testing of remineralization ability, as well as its mechanical and physical properties [30].

The study demonstrated that the presence of ACTIVA ${ }^{\mathrm{TM}}$ BioACTIVE Restorative in contact with demineralized dentin surfaces induced remineralization of the demineralized dentin surface. Interestingly, the remineralizing test in phosphate-containing solution revealed that the ACTIVA ${ }^{\mathrm{TM}}$ placed in close contact with demineralized dentin can induce remineralization of the phosphorous-depleted demineralized dentin surface down to a $30-50 \mathrm{~mm}$ depth within a period of 28 days, as proved by the EDX compositional depth profile.

The availability of mineral ions (calcium and fluoride) from restorative materials in the remineralizing process is the basic requirement to augment the apatite formation ability and mineralization of dentin in the presence of phosphate-containing solutions.

In the present study, the presence of calcium in the surrounding medium demonstrated a notable effect on dentin remineralization: the data showed that ACTIVA $^{\text {TM }}$ produced a significant remineralization of the demineralized adjacent dentin by calcium/mineral uptake, as demonstrated by EDX data.

The cross-section EDX line-scanning profiles of the samples are displayed in Figure 3 , which suggested that after using EDTA $17 \%$ for $2 \mathrm{~h}$, dentin was demineralized for approximately $50 \mu \mathrm{m}$, and the demineralized dentin in contact with ACTIVA ${ }^{\text {TM }}$ BioACTIVE revealed a notable remineralization, which was supported by the findings for calcium and phosphate ion release since they play an important role in remineralization process. On the other hand, Filtek Z350 XT did not show any remineralization that also comes in line with the study results for the absence of ion release.

According to calcium and phosphate ion release data (Table 1), ACTIVA ${ }^{\mathrm{TM}}$ showed greater remineralization ability than Filtek Z350 XT. Interestingly, the former composite showed more prominent bands than the latter (Figure 3) which might be due to its bioactive glass fillers.

Regarding calcium and phosphate ion release, the results showed that ACTIVA ${ }^{\mathrm{TM}}$ released calcium and phosphate ions throughout the different storage times steadily unlike Filtek Z350 XT which did not release any and that might be due to the relatively higher stability of the matrix structure and fillers of 
composite resins, and absence of glass matrix and bioactive components in its composition, which was in agreement with Ruengrungsom et al. [31]. However, the result of the study was in contrast to a previous study [32], which reported that ACTIVA ${ }^{\mathrm{TM}}$ showed negligible calcium ion release after $24 \mathrm{~h}$ and after 28 days.

The decline of calcium release throughout the different storage times might be attributed to a change with time in the concentration gradient. When the discs were first placed in deionized water, the concentration gradient was large, and calcium diffused rapidly from the discs. Moreover, the rate of calcium release decreased, that was as a result of developing a smaller concentration gradient as more calcium was released into the solution.

By observing the data obtained from the present study considering the bond strength results, ACTIVA $^{\mathrm{TM}}$ when used without adhesive showed low micro-shear bond strength which was unlike the manufacturer claims of the unnecessity of adhesive use, which was in agreement with Van Dijken et al. [33], who conducted a randomized clinical trial, which in turn resulted in a non-acceptable very high failure frequency after a 1-year period. The causes of ACTIVA TM failures were probably multifactorial. Too weak initial bond to the cavity walls was believed to be the main factor that could not withstand the polymerization stress.

In September 2017, the manufacturer recommended the use of an adhesive layer only in non retentive cavity preparations. Still, several studies [33], [34] doubted the longevity of the restoration without using the adhesive. Therefore, in March 2019, the manufacturer's instructions recommended the use of adhesive system as a mandatory step. This supported the findings that ACTIVA ${ }^{T M}$ with adhesive showed comparable results as the conventional resin composite.

Regarding wear results of the study, the wear of ACTIVA BioACTIVE Restorative was equivalent to that of the composite resin. The results of the study were consistent with Bansal et al. [35], who showed that ACTIVA ${ }^{\text {TM }}$ had similar wear rate as a conventional resin composite. This can be explained partially by the resilient resin matrix with energy-absorbing elastomeric components [20].

The obtained results of the present study were in agreement with those of Latta et al. [36], who concluded that wear values of ACTIVA ${ }^{\mathrm{TM}}$ were comparable to Fuji Equia Forte and a newly developed resin composite. In addition, Garoushi et al. [20], and Roulet et al. [37], reported that (ACTIVA ${ }^{\mathrm{TM}}$ ) had lower wear rates than those of other tested materials.

\section{Conclusion}

ACTIVA ${ }^{\mathrm{TM}}$ BioACTIVE seems to be a promising restorative material. ACTIVA ${ }^{\mathrm{TM}}$ induced remineralization of demineralized dentin appearing to be a bioactive material. Additionally, ACTIVA released calcium and phosphate ions throughout the tested time intervals, whereas Filtek Z350 XT did not. Regarding micro-shear bond strength and wear resistance, it showed comparable results to the conventional resin composite which suggests that it can be a good substitute for Filtek Z350 XT. ACTIVA ${ }^{\text {TM }}$ could serve as a restorative material of choice as it combined the mechanical properties of the conventional resin composite with an additional bioactivity.

\section{Recommendations}

Clinical studies are recommended to compare the clinical performance of ACTIVA ${ }^{\mathrm{TM}}$ with the other restorative materials.

\section{References}

1. El-Mansy LH, Ali MM, Hassan RELS, Beshr KA, El Ashry SH Evaluation of the biocompatibility of a recent bioceramic root canal sealer (Bioroot ${ }^{\mathrm{TM}}$ rcs): In-vivo study. Open Access Maced J Med Sci. 2020;8:100-6. https://doi.org/10.3889/oamjms.2020.4361

2. Zaki DY, Zaazou MH, Khallaf ME, Hamdy TM. In vivo comparative evaluation of periapical healing in response to a calcium silicate and calcium hydroxide based endodontic sealers. Open Access Maced J Med Sci. 2018;6(8):1475-9. https://doi.org/10.3889/ oamjms.2018.293

PMid:30159080

3. Alagha E, Samy AM. Effect of different remineralizing agents on white spot lesions. Open Access Maced J Med Sci. 2021;9:148. https://doi.org/10.3889/oamjms.2021.5662

4. Demarco FF, Corrêa MB, Cenci MS, Moraes RR, Opdam NJ Longevity of posterior composite restorations: Not only a matter of materials. Dent Mater. 2012;28(1):87-101. https://doi. org/10.1016/j.dental.2011.09.003

PMid:22192253

5. Ferracane JL. Resin composite-state of the art. Dent Mater. 2011;27(1):29-38.

PMid:21093034

6. Drummond JL. Degradation, fatigue, and failure of resin dental composite materials. J Dent Res. 2008;87(8):710-9. https://doi. org/10.1177/154405910808700802

PMid: 18650540

7. Bayne SC. Dental biomaterials: Where are we and where are we going? J Dent Educ. 2005;69(5):571-85. https://doi. org/10.1002/j.0022-0337.2005.69.5.tb03943.x PMid:15897337

8. Watts DC, Marouf AS, Al-Hindi AM. Photo-polymerization shrinkage-stress kinetics in resin-composites: Methods development. Dent Mater. 2003;19(1):1-11. https://doi. org/10.1016/s0109-5641(02)00123-9 PMid: 12498890

9. Ferracane JL. Models of caries formation around dental composite restorations. J Dent Res. 2017;96(4):364-71. https:// 
doi.org/10.1177/0022034516683395

PMid:28318391

10. De Munck J, Van Landuyt K, Peumans M, Poitevin A, Lambrechts $\mathrm{P}, \mathrm{Braem} \mathrm{M}$, et al. A critical review of the durability of adhesion to tooth tissue: Methods and results. J Dent Res. 2005;84(2):11832. https://doi.org/10.1177/154405910508400204 PMid: 15668328

11. Hamdy T. Polymerization shrinkage in contemporary resin-based dental composites: A review article. Egypt J Chem. 2021;64(6):3087-92. https://doi.org/10.21608/ ejchem.2021.60131.3286

12. Gandolfi MG, Taddei P, Siboni F, Modena E, De Stefano ED, Prati C. Biomimetic remineralization of human dentin using promising innovative calcium-silicate hybrid "smart" materials. Dent Mater. 2011;27(11):1055-69. https://doi.org/10.1016/j. dental.2011.07.007

PMid:21840044

13. Hench LL, Splinter RJ, Allen WC, Greenlee TK. Bonding mechanisms at the interface of ceramic prosthetic materials. J Biomed Mater Res. 1971;5(6):117-41. https://doi.org/10.1002/ jbm.820050611

14. Hench LL. The story of Bioglass. J Mater Sci Mater Med. 2006;17(11):967-78.

PMid: 17122907

15. Combes C, Rey C. Amorphous calcium phosphates: Synthesis, properties and uses in biomaterials. Acta Biomater. 2010;6:336278. https://doi.org/10.1016/j.actbio.2010.02.017

16. Zhao J, Liu Y, Sun W, Zhang H. Amorphous calcium phosphate and its application in dentistry. Chem Central J BioMed Central. 2011;5:40.

PMid:21740535

17. Jandt KD, Sigusch BW. Future perspectives of resin-based dental materials. Dent Mater. 2009;25(8):1001-6. https://doi. org/10.1016/j.dental.2009.02.009

PMid:19332352

18. Ryou H, Niu LN, Dai L, Pucci CR, Arola DD, Pashley DH, et al. Effect of biomimetic remineralization on the dynamic nanomechanical properties of dentin hybrid layers. J Dent Res. 2011;90(9):1122-8. https://doi.org/10.1177/0022034511414059 PMid:21730254

19. Abdelnabi A, Hamza MK, El-Borady OM, Hamdy TM. Effect of different formulations and application methods of coral calcium on its remineralization ability on carious enamel. Open Access Maced J Med Sci. 2020;8:94-9. https://doi.org/10.3889/ oamjms.2020.4689

20. Garoushi S, Vallittu PK, Lassila L. Characterization of fluoride releasing restorative dental materials. Dent Mater $\mathrm{J}$. 2018;37(2):293-300. https://doi.org/10.4012/dmj.2017-161 PMid:29279547

21. BioACTIVE Dual Cure Products. Product Description. BioACTIVE-BASE/LINER TM Moisture Friendly Dual Cure Fluoride Releasing Radiopaque ACTIVA. India: BioACTIVE Dual Cure Products; 2016. p. 2-3.

22. Jun SK, Lee JH, Lee HH. The biomineralization of a bioactive glass-incorporated light-curable pulp capping material using human dental pulp stem cells. Biomed Res Int. 2017;2017:2495282. https://doi.org/10.1155/2017/2495282 PMid:28232937

23. Gandolfi MG, Siboni F, Primus CM, Prati C. Ion release, porosity, solubility, and bioactivity of MTA plus tricalcium silicate. J Endod. 2014;40(10):1632-7. https://doi.org/10.1016/j.joen.2014.03.025 PMid:25260736

24. Awosanya K, Nicholson JW. A study of phosphate ion release from glass-ionomer dental cements. J Mater Sci.
2014;58(3):210-4.

25. Arab M, Al-Sarraf E, Al-Shammari M, Qudeimat M. Microshear bond strength of different restorative materials to teeth with molar-incisor-hypomineralisation (MIH): A pilot study. Eur Arch Paediatr Dent. 2019;20(1):47-51. https://doi.org/10.1007/ s40368-018-0384-2

PMid:30406461

26. Bumrungruan $\mathrm{C}$, Sakoolnamarka R. Microshear bond strength to dentin of self-adhesive flowable composite compared with total-etch and all-in-one adhesives. J Dent Sci. 2016;11(4):44956. https://doi.org/10.1016/j.jds.2016.08.003

27. Torres GB, da Silva TM, Basting RT, Bridi EC, França FM, Turssi CP, et al. Resin-dentin bond stability and physical characterization of a two-step self-etching adhesive system associated with TiF4. Dent Mater. 2017;33(10):1157-70. https:// doi.org/10.1016/j.dental.2017.07.016

PMid:28781068

28. Balamurugan A, Balossier G, Michel J, Kannan $S$, Benhayoune H, Rebelo AH, et al. Nanoleakage and microshear bond strength in deproteinized human dentin. J Biomed Mater Res. 2007;5(3):546-53.

PMid: 17022053

29. Gwon B, Bae E Bin, Lee JJ, Cho WT, Bae HY, Choi JW, et al. Wear characteristics of dental ceramic CAD/CAM materials opposing various dental composite resins. Materials (Basel). 2019;12(11):1839. https://doi.org/10.3390/ma12111839 PMid:31174298

30. Fugolin AP, Pfeifer CS. New resins for dental composites J Dent Res. 2017;96(10):1085-91. https://doi. org/10.1177/0022034517720658

PMid:28732183

31. Ruengrungsom C, Burrow MF, Parashos P, Palamara JE. Evaluation of $\mathrm{F}, \mathrm{Ca}$, and $\mathrm{P}$ release and microhardness of eleven ion-leaching restorative materials and the recharge efficacy using a new $\mathrm{Ca} / \mathrm{P}$ containing fluoride varnish. J Dent. 2020;102:103474. https://doi.org/10.1016/j.jdent.2020.103474 PMid:32941973

32. Koutroulis A, Kuehne SA, Cooper PR, Camilleri J. The role of calcium ion release on biocompatibility and antimicrobial properties of hydraulic cements. Sci Rep. 2019;9(1):19019. https://doi.org/10.1038/s41598-019-55288-3

33. van Dijken JW, Pallesen U, Benetti A. A randomized controlled evaluation of posterior resin restorations of an altered resin modified glass-ionomer cement with claimed bioactivity. Dent Mater. 2019;35(2):335-43. https://doi.org/10.1016/j. dental.2018.11.027

PMid:30527586

34. Benetti AR, Michou S, Larsen L, Peutzfeldt A, Pallesen U, van Dijken JW. Adhesion and marginal adaptation of a claimed bioactive, restorative material. Biomater Investig Dent. 2019;6(1):90-8. https://doi.org/10.1080/26415275.2019.1696202 PMid:31998876

35. Bansal R, Burgess J, Lawson NC. Wear of an enhanced resin-modified glass-ionomer restorative material. Am J Dent. 2016;29(3):171-4. PMid:27505995

36. Latta MA, Tsujimoto A, Takamizawa T, Barkmeier WW. In vitro wear resistance of self-adhesive restorative materials. J Adhes Dent. 2020;22(1):59-64 PMid:32030376

37. Roulet JF, Hussein $\mathrm{H}$, Abdulhameed NF, Shen C. In vitro wear of two bioactive composites and a glass ionomer cement. Dtsch Zahnärztliche Zeitschrift Int. 2019;1(1):24-30. 